\title{
VISÕES SOBRE O ISEB: PERSPECTIVAS E APONTAMENTOS CRÍTICOS SOBRE O INSTITUTO
}

\author{
Hugo D. C. Muller ${ }^{1}$
}

\begin{abstract}
Resumo
O presente artigo visa debater como que as Ciências Sociais se debruçaram sobre o Instituto Superior de Estudos Brasileiros após a sua extinção. A partir de um balanço crítico de obras referenciais sobre o Instituto, apontaremos alguns recursos teóricos e analíticos que se tornaram constantes. Proporemos a distinção entre duas fases das Ciências Sociais brasileira acerca do ISEB: a "fase crítica" e a "fase de reabilitação".
\end{abstract}

Palavras-chave: ISEB; Nacionalismo; Ideologia; Pensamento político; Desenvolvimentismo.

\begin{abstract}
This article aims to discuss how the Social Sciences looked at the Instituto Brasileiro de Estudos Brasileiros after its extinction. Based on a critical review of reference works about the Institute. The article proposes the distinction between two phases of the Brazilian Social Sciences about ISEB: the "critical phase" and the "rehabilitation phase".
\end{abstract}

Keywords: ISEB; Nationalism; Ideology; Political thought; Developmentalism.

\footnotetext{
1 Mestre em História Política pela Universidade do Estado do Rio de Janeiro (UERJ).
} Pesquisador na mesma universidade. E-mail: hugomuller.rj@gmail.com 


\section{Introdução}

Pretendemos fazer um balanço crítico sobre o tratamento que a área das Ciências Sociais dispensou ao Instituto Superior de Estudos Brasileiros. ${ }^{2}$ Neste sentido, identificaremos dois momentos distintos: uma primeira fase, durante toda a década de 1970, que formulou duras críticas ao Instituto, tanto em seu caráter político quanto teórico; e uma segunda fase, que se inicia em meados da década de 1980 e vai até os dias atuais, reabilitando o ISEB na sua dimensão política e teórica. Nomeamos, respectivamente, de "fase crítica" e "fase de reabilitação".

Como veremos ao longo do artigo, tais fases não significam períodos impenetráveis de visões dissonantes, porém, caracterizadas por perspectivas sociológicas dominantes em relação ao ISEB. Esse trabalho não pretende realizar um levantamento bibliográfico sobre o Instituto, portanto, muitas obras que relacionadas ao tema não foram incluídas ${ }^{3}$, assim como não se trata de um balanço crítico total, mas depreendemos elementos e características desta trajetória sociológica que, ao menos, são capazes de formar um panorama geral da crítica nos últimos 50 anos.

O critério de escolha das obras analisadas tem como intuito selecionar produções que se tornaram referenciais para as Ciências Sociais e outras que contenham perspectivas capazes de refletir as fases que elas estão inseridas. Descartamos produções posteriores de autores isebianos e/ou que participaram ativamente do período em questão.

\footnotetext{
${ }^{2}$ Ao nos referirmos às Ciências Sociais estamos englobando, de forma mais ampla, os estudos do pensamento social e político brasileiro que vão além da área estrita da sociologia. Abarcando filósofos e historiadores.

${ }^{3}$ Nas décadas de 1950 e 1960 houve escritos que envolviam visões críticas a respeito da produção de determinados isebianos. Em 1958, Florestan Fernandes discordou da concepção de sociologia desenvolvida por Alberto Guerreiro Ramos. Em 1963 será a vez de Gérard Lebrun escrever um artigo com apontamentos críticos as formulações epistemológicas de Álvaro Vieira Pinto. Porém, as críticas mais aprofundadas, sistematizadas e que abarcaram o Instituto como um todo foram iniciadas na década de 1970. Em relação às décadas posteriores, citamos aqui algumas obras relevantes que não foram incluídas, porém, sem prejuízo ao balanço crítico proposto por este artigo: Por uma sociologia das Ciências Sociais (1989), de Sérgio Miceli; Ideologia da cultura brasileira (1975), de Carlos Guilherme Mota; Da Sociologia em mangas de camisa à túnica inconsútil do saber (1995), de Clóvis Brigagão. Ideologia e desenvolvimento: Brasil, 1930-1964 (1997), de Ricardo Bielschowsky.
} 
Para a fase crítica analisamos ISEB: Fábrica de Ideologias (1974), de Caio Navarro de Toledo e "O tempo das ilusões" (1976) de Maria Sylvia de Carvalho Franco, dois trabalhos que se tornaram clássicos sobre o tema. Também analisaremos o texto de Alzira Abreu intitulado "A ação política dos intelectuais do ISEB", parte da conclusão de sua tese de doutorado de 1975, e o artigo "O ISEB: notas à margem de um debate" (1978), escrito por Bolívar Lamounier. As duas últimas obras mencionadas não se inserem no "núcleo duro" da crítica uspiana, porém, foram produzidas no período de intensa "crítica" ao Instituto. Por fim, realizaremos alguns apontamentos sobre a obra organizada por Toledo, em ocasião dos cinqüenta anos da criação do ISEB, Intelectuais e política no Brasil, a experiência do ISEB (2005).

Para a fase da reabilitação nos debruçamos sobre Cultura Brasileira e Identidade Nacional de Renato Ortiz, Os intelectuais e a política no Brasil de Daniel Pécaut, dois clássicos que contribuíram para sedimentar as visões alternativas à primeira fase; "O ISEB nos bancos dos réus" de Luiz Eduardo Motta, já fruto da crítica estabelecida às abordagens da sociologia paulista, e, por fim, "Os Cadernos do povo brasileiro e o debate nacionalista nos anos 1960: um projeto de revolução brasileira" de Angélica Lovatto, exemplo de pesquisa que não aborda especificamente o Instituto, mas que se inclui nesta fase de reabilitação do ISEB.

\section{A fase crítica: os críticos da ideologia}

Os primeiros estudos sobre o ISEB no Brasil ocorreram na década de 1970 e partiram da sociologia paulista, com a tese de Caio Navarro de Toledo ISEB: Fábrica de Ideologias, de 1974 e publicada em 1977; o livro Ideologia da cultura brasileira, de 1975 de Carlos Guilherme Mota; e "O tempo das Ilusões" de Maria Sylvia de Carvalho Franco, de 1976. 0 intuito central de tais obras era realizar uma crítica à produção da "ideologia de desenvolvimento" por parte dos isebianos que escamoteava a luta de classes no Brasil. Para além de criticar a opção pelo desenvolvimento do capitalismo nacional, a crítica uspiana atinge a epistemologia isebiana ao se referir às suas produções enquanto ideológicas e não científicas, sendo reservado à 
Instituição o papel de promotor de ideologia da classe dominante. Portanto, a categoria de ideologia era cara a esta fase crítica ao ISEB. Constitui-se como uma fase, pois tais críticas consolidam um determinado pensamento da época que partem de um lugar intelectual específico, porém, que influencia toda a intelectualidade brasileira.

Gostaria de salientar, também, que este trabalho retoma, na produção ligada ao Departamento de Filosofia da USP, a pesquisa sobre o pensamento brasileiro, a associando a esse exame particular, a preocupação mais de estudo e crítica das principais correntes teóricas modernas, procurando captar as ligações entre as determinações particulares de nossa sociedade e o movimento de universalização do próprio capitalismo (FRANCO, 1977, p.14).

Caio Navarro de Toledo em sua referida obra parte das perspectivas de Althusser para discutir a categoria de ideologia, nas quais a ideologia está intrinsecamente ligada ao conceito de luta de classes. Vale ressaltar que essa é uma visão geral do marxismo e não somente do marxista francês. Mas especificamente, como bem escreve Toledo, Althusser irá compreender a ideologia como um "falseamento" da realidade e obra da burguesia, instrumento de domínio sobre a classe trabalhadora. Em contraposição à ideologia, o instrumento de libertação da classe trabalhadora seria a ciência para realizar a luta de classes.

Portanto, a luta de classes e a luta ideológica aqui se transmutam na oposição entre ciência e ideologia. A ideologia - que é entendida como a ideologia em geral de uma sociedade de classes (não se fala, pois, em ideologias de classe) - é a ideologia da classe dominante: mistificadora, dissimuladora, deformadora etc. A Ciência se transforma, assim, no aliado ou no instrumento natural das classes dominadas. A ela se confere uma função bem determinada: "subversão" da relação de dominação ideológica (TOLEDO, 1977, p. 22).

Toledo irá problematizar a concepção althusseriana, a distinção entre ideologia e ciência, em dois pontos: no primeiro ponto critica a visão "idealista" da ciência, alertando que esta é controlada, também, pelas camadas dominantes da sociedade. No segundo ponto relativiza uma visão abstrata e formal da distinção entre ideologia e ciência, afirmando que a ideologia pode conter certa parcela de conhecimento e não ser inteiramente 
"enganosa", assim como a própria ciência pode ser "ideologizada". Sendo assim, o autor defende que a melhor delimitação entre ideologia e ciência se dará a partir de uma análise da experiência concreta desta categoria. Nesta perspectiva teórica althusseriana, que Toledo analisou a produção ideológica do ISEB, qualificando-a no campo da ideologia e não da ciência, o termo "fábrica" em seu título já alude a uma produção de caráter mecânica, desposada do ofício artesanal de se pensar cientificamente.

$\mathrm{O}$ autor afirma que o ISEB promoveu as ideologias em uma perspectiva contrária à tendência das ciências sociais da época. Em uma pesquisa de fôlego, Toledo identifica as concepções acerca da ideologia desenvolvidas pelos isebianos e a construção da ideologia do desenvolvimento. Alberto Guerreiro Ramos, Cândido Mendes e Roland Corbisier têm as elaborações de Hélio Jaguaribe como referências, Álvaro Vieira Pinto conceitua a ideologia com algumas diferenças, mas, segundo Toledo, surtindo o mesmo efeito prático em prol da ideologia do desenvolvimento. Toledo aponta que Jaguaribe opera a categoria no sentido da "representatividade" e "autenticidade", ou seja, a ideologia pode ou não representar os interesses de uma determinada classe social e são mais ou menos autênticas dependendo se ela promove ou não a evolução da sociedade. ${ }^{4} \mathrm{Na}$ então atual etapa do país, segue Toledo acerca das formulações isebianas, a ideologia do desenvolvimento seria representativa para todas as classes e autêntica para o Brasil.

Ou seja, os setores dominantes de todas as classes sociais têm os mesmos interesses situacionais (transformação social) e estes interesses situacionais, por sua vez, coincidem com as necessidades objetivas de todo o país (a expansão das suas forças materiais de produção) (TOLEDO, 1977, p. 42).

\footnotetext{
${ }^{4}$ Segundo Jaguaribe a ideologia opera através de duas correspondências: relacionada à determinada classe social e a um determinado processo histórico-social. Na primeira relação, a ideologia pode ser mais ou menos "representativa" conforme atenda e corresponda às necessidades da classe em questão. Na segunda, a ideologia poder mais ou menos "autêntica", conforme corresponda às capacidades de evolução e desenvolvimento da estrutura-tipo de uma comunidade. Portanto, o debate acerca da ideologia está baseado em sua "representação" perante os interesses de uma classe e em sua "autenticidade" em relação à evolução de uma sociedade. São nesses termos que Hélio Jaguaribe irá operar o conceito de ideologia. Desta forma, o esforço do autor estará centrado em identificar a ideologia autêntica do Brasil e representativa para suas classes sociais (MULLER, 2019, p. 67).
} 
A interpretação de Caio Navarro sobre a visão isebiana do efeito da ideologia do desenvolvimento nas classes sociais tende a enfatizar a ausência de conflitos entre a burguesia e o proletariado e atenuar seus efeitos de disputas dentro da própria burguesia. Assim como é verdade que a ideologia do desenvolvimento é a mais representativa para burguesia, pois esta é capaz de desenvolvê-la enquanto classe em sua versão mais moderna, por outro lado, Hélio Jaguaribe apresenta a necessidade dos setores latifundiários e mercantilistas da burguesia se adequarem ou sucumbirem a esta ideologia.

No trecho acima, ao se referir aos setores dominantes, Caio Navarro de Toledo comete uma imprecisão já que o conceito de classe dominante apresentado por Jaguaribe se divide em duas definições mais específicas: a política e a econômica. Pois, o isebiano identifica um "descompasso" no Brasil entre o setor que exercia o poder político (mercantilismo) e o setor economicamente mais ativo (industriais). Numa visão geral, a classe dominante era apresentada pelos isebianos enquanto a "burguesia mercantilista". A ligação do isebianos - e sua ideologia do desenvolvimento à conciliação de classes, permitindo qualificá-los enquanto produtores de uma ideologia dominante, era a tônica desta primeira fase crítica da sociologia sobre o ISEB. Porém, tal imprecisão acima mencionada se explica pela própria crítica do autor à ausência de uma reflexão teórica mais aprofundada sobre as classes sociais por parte do Instituto. "Estas são invocadas pela análise apenas para ressaltar a contradição dominante ou principal da sociedade brasileira e justificar o projeto ideológico nacional desenvolvimentista." (TOLEDO, 1977, p. 120).

A ideologia do desenvolvimento enquanto condição fundamental para o desenvolvimento do Brasil seria promovida pela inteligência nacional, neste sentido, os isebianos se emanavam de uma grande responsabilidade de agir enquanto uma intelligentsia. Destacamos e identificamos dois argumentos, que estão vinculados entre si, que sustentam a tese de Toledo e Maria Sylvia de Carvalho Franco de que o Instituto produziria ideologia e não ciência. 0 primeiro argumento foi explícito em um subtítulo da referida obra de Toledo, refere-se à "ciência tutelada", ou seja, a ideologia isebiana passou 
dos limites de ser um instrumento de transformação da realidade e virou condição, um caminho, para o conhecimento, iluminando-o, o que seria papel da própria ciência. 0 conhecimento enquanto função da ideologia residiria no projeto prévio de desenvolvimento da nação para a transformação da consciência da sociedade. "A ideologia parece, assim, desempenhar a mesma função cognoscente da ciência ("decifrar"), ou antes, tem ela o privilégio de ser simultaneamente, de um lado prática, ação, e, do outro lado, conhecimento." (TOLEDO, 1977, p. 52).

Desta forma, Toledo afirma que ocorre uma "ideologização" da ideologia, consistindo na hegemonia da ideologia do desenvolvimento sobrepondo-se às outras categorias sociológicas e até mesmo à ciência.

O segundo argumento aponta que a produção isebiana contém imprecisões e equívocos de cunho teórico, como afirma Franco na apresentação da obra ISEB: Fábrica de Ideologias:

Longe de ser uma frouxa, despropositada, inocente fraseologia, o pensamento isebiano está firmemente amarrado num sistema cujas inconsistências teóricas mesmas o sustentam em sua eficácia prática, confluindo no processo de afirmação do capitalismo (CARVALHO, 1977, p. 14).

Tais "inconsistências teóricas", que afastam os isebianos de um trabalho científico, se referem ao mau uso de categorias clássicas do marxismo. Sendo, para os críticos paulistas, o conceito de "alienação" a principal "vítima” dos “arranjos indigenistas”, como qualifica Franco (1985, p. 165). Toledo observa que há na base das formulações isebianas sobre a ideologia e o desenvolvimento nacional a categoria de "alienação"5, na medida em que, para os isebianos, a ausência de tal ideologia configura-se uma alienação da estrutura social brasileira. A frase de Roland Corbisier, "tudo é colonial na colônia", com forte influência teórica de Jean Paul Sartre e Georges Balandier, como bem destaca Toledo, dá uma dimensão da globalidade alienada imputada ao país que vivia em "situação colonial". A alienação pressupunha uma dependência, categoria esta que era basilar para

\footnotetext{
${ }^{5}$ Hélio Jaguaribe não elabora especificamente a respeito desta categoria, porém, como aponta Caio Navarro de Toledo, o conceito de "inautenticidade" tem uma correspondência com o de "alienação".
} 
as conceituações do isebianos sobre colonialismo e subdesenvolvimento. A alienação está inserida dentro do tema da "nação", cara e central aos isebianos: "a dependência para todos os autores isebianos se explica em termos de nação." (TOLEDO, 1977, p. 69). Nesta altura, Toledo e Franco apontam que ocorre um deslizamento do conceito de "alienação", do "trabalho" para a "nação", os isebianos defendem que a libertação da alienação do país se dará a partir da sua emancipação e não em uma perspectiva de classes. O ISEB opera essa análise em uma perspectiva situacional, o argumento forte utilizado por vários autores do Instituto consiste, sinteticamente, de que a principal contradição que emperrava o desenvolvimento era a dependência, visto que, por conseguinte, o verdadeiro "corpo social" não estava formado no país e nem as classes exauriram suas contradições, ou, como afirma Jaguaribe, os setores capazes de desenvolver as condições de produção no país (o capitalismo) deveriam se tornar setores de fato dominantes em suas classes sociais.

Desta forma, o desenvolvimento econômico surge no horizonte representando, simultaneamente, a ruptura com o subdesenvolvimento, a conquista da autonomia e a realização ou "recuperação do ser histórico" da comunidade (de que apartara o sistema colonial) (TOLEDO, 1977, p.72).

Houve uma forte influência do pensamento hegeliano nas produções isebianas ao relacionar a "alienação" e a sua superação à consciência em geral de uma comunidade. Interessante o destaque que Toledo faz sobre o trecho da obra Nacionalismo e Desenvolvimento de Cândido Mendes, de 1963, no qual o isebiano irá utilizar a "dialética do Senhor e do Escravo", de Hegel, para pensar a relação entre o centro e a periferia. Enquanto a metrópole seria o sujeito, a colônia seria o objeto, e ao final, a colônia não se constituiu enquanto "ser", pois era produto das decisões e ações do "ser" metrópole. Mendes afirma que a colônia, ao exportar a matéria-prima, estaria enviando o "não-ser" e ao importar produtos acabados receberia a essência da metrópole (TOLEDO, 1977, p. 72). Toledo apresenta tal visão como ideológica sem uma correspondência sociológica entre tal dialética hegeliana e as referências utilizadas por Mendes. 
Franco e Toledo apontam uma leitura isebiana das categorias desenvolvidas por Karl Marx em sua fase jovem, na qual o conceito de "alienação do trabalho" era pouco desenvolvido e não estava na centralidade de suas teses, ainda muito influenciadas pela filosofia de Hegel e Feuerbach ${ }^{6}$. A crítica se estende à ausência de uma análise sobre a categoria de "modo de produção":

[...] parece-nos que a alienação é entendida como fenômeno apenas específico da nação subdesenvolvida. Ignora-se que, mesmo realizado o desenvolvimento econômico, não deixará de estar nos marcos de um modo de produção [...] (TOLEDO, 1977, p. 80).

Os paulistas notam que se o conceito de "alienação" ligado ao "trabalho" ainda era imaturo na fase inicial de Marx, o "modo de produção" foi uma categoria sempre presente em suas análises. Os críticos paulistas vão além de qualificá-los apenas como leitores de um jovem Marx, adjetivam como "imprecisos" e "parciais" em suas leituras do filósofo alemão (FRANCO, 1977, p. 174).

Os apontamentos de Toledo e Franco a uma leitura equivocada de Karl Marx por parte do ISEB se baseiam na produção de apenas um isebiano: Álvaro Vieira Pinto, em sua obra clássica Consciência e Realidade Nacional (1960). Apesar desse intelectual ter sido, entre os isebianos, o que mais se aprofundou no conceito de alienação e a despeito da sua influência sobre outros intelectuais do Instituto, ocorreu uma generalização da crítica paulista a todo o ISEB. Por parte dos demais isebianos, se formos analisar em bloco, a categoria de "alienação" e suas variações está mais ligada aos referenciais teóricos do "idealismo" alemão e do "existencialismo" francês do que as formulações de Karl Marx.

Em 1978, Bolívar Lamounier publicou o artigo intitulado “O ISEB: notas à margem de um debate". 0 cientista social teve sua formação em sociologia na UFMG, com posterior formação em Ciências Políticas na Universidade da Califórnia (EUA). A escrita de Lamounier nos indica que o debate em torno do Instituto era algo notório no período, assim como a própria obra de Caio

6 Aqui Toledo cita a influência dos Manuscritos de 1844, de Karl Marx, nas produções de Álvaro Vieira Pinto. 
Navarro de Toledo: "ampla difusão do livro, como também o debate que em torno dele se estabeleceu na imprensa (...)". (LAMOUNIER, 1978, p. 153). Mesmo elogiando a profundidade e sistematicidade da obra ISEB: Fábrica de ideologias, Lamounier pondera a ausência de uma relação entre a análise teórica sobre o ISEB com o contexto da época. Tal fato teria levado o filósofo paulista a cometer um anacronismo: cobrar certo nível de interpretação sociológica da realidade que não era realizada na época. Lamounier cita o exemplo da crítica de Toledo à ausência de uma teoria sobre as classes sociais por parte dos isebianos, pois, se "perguntarmos o que é que se sabia, no Brasil, em meados dos anos cinqüentas, a partir das análises empíricas, a questão muda de figura" (LAMOUNIER, 1978, p.155). Outro exemplo trata-se do tema do nacionalismo, tratado pela sociologia paulista como "mistificadora". O cientista mineiro indica o tratamento da categoria de "nacionalismo" de forma abstrata, sem estabelecer seus impactos políticos no contexto histórico em questão, ou como afirmar o autor, "sem se perguntar se o nacionalismo merecia ou não a qualificação de progressista que frequentemente se atribuía; ou, melhor ainda, quando merecia, sob que aspectos a merecia, e assim por diante." (LAMOUNIER, 1978, p.156). Porém, longe de "reabilitar" a importância intelectual e política do Instituto, Lamounier, a essa altura, está mais preocupado em levantar certas imprecisões ao tratamento dado a ISEB, como afirmou o autor sobre o Instituto: "penso mesmo que ele possa conter mais equívocos do que acertos" (LAMOUNIER, 1978, p.158).

As críticas de Caio Navarro de Toledo e Maria Sylvia de Carvalho Franco partem de um lugar resistente às formulações teóricas de cunho "nacionalista", assim como de um contexto político que motivou muitos cientistas sociais a tentarem entender os motivos do golpe empresarialmilitar, consolidando a visão de que o colapso das políticas identificadas como "populistas" - que inclui o nacional-desenvolvimentismo em seu espectro - foi um fator determinante. Daí o tom combativo de vários textos, os debates que suscitam e a emergência da "burguesia nacional" e do 
movimento sindical não mais em uma confortável posição de promotores do desenvolvimento do país (GOMES, 1996, p. 7).

A sociologia uspiana, como cita o próprio Toledo, não estabelecia um diálogo e debate com os intelectuais isebianos: "As ideologias isebianas jamais tiveram guarida no seio desta camada de intelectuais." (TOLEDO, 1977, p. 26). A obra de Toledo se torna a primeira a fazer uma crítica sólida e aprofundada ao "nacional-desenvolvimentismo" na dimensão de sua intelectualidade. Porém, se por um lado, o autor rompe com essa negligência proposital ao ISEB, por outro, reafirma, como resultado de sua obra, a concepção uspiana de que os isebianos não foram intelectuais compatíveis para tratarem do tema do capitalismo brasileiro. "A razão disso parece ser muito simples: em nenhum momento se reconhece a Instituição como possível interlocutor para um debate em comum acerca dos problemas que afetavam o capitalismo dependente brasileiro" (TOLEDO, 1977, p. 26).

Do outro lado, essa "rejeição" intelectual era sentida e apesar de não poderem respondê-la à altura - visto que os isebianos tiveram seu Instituto literalmente destruído e foram impedidos de lecionarem em Universidades proferiram opiniões esparsas a respeito da crítica uspiana. Angélica Lovatto, em sua tese de doutorado, resgata as críticas de Nelson Werneck Sodré na obra História e materialismo histórico no Brasil, de 1987, às produções desta fase da sociologia paulista. ${ }^{7}$ A autora aponta que Sodré considerava Toledo um "intérprete honesto", ao contrário de Carlos Guilherme Mota, mas com insuficiências pela sua formação uspiana; por outro lado, não poupava críticas à Maria Sylvia de Carvalho Franco e Francisco Weffort, acusados de "falsear a imagem" do ISEB.

Sodré qualifica os uspianos de omissos, a respeito da postura passiva diante da destruição do ISEB pela ditadura empresarial-militar. Com ironia, Nelson Werneck Sodré respondeu às colocações de Toledo por ter se referido a ele se utilizando dos termos "pretende ser marxista" e "se considera filiado ao marxismo":

\footnotetext{
7 Apesar de Nelson Werneck Sodré ter sido "poupado" por Toledo em algumas críticas formuladas na obra ISEB: Fábrica de Ideologias.
} 
Estudioso do marxismo, não alcancei, nesse campo, certamente, às alturas teóricas da sra. Maria Sylvia de Carvalho Franco ou do sr. Francisco Corrêa Weffort, que parece, são os marxistas clássicos e modelares para o sr. Caio Navarro de Toledo. Peço apenas que ele não me recuse entrada em recinto presidido por autoridades tão conspícuas e me conceda, quando menos, um certificado de frequência. No espetáculo em que eles ocupam a tribuna de honra, reivindico apenas um lugarzinho na geral (SODRÉ apud LOVATTO, 2010, pp. 362-363).

Luiz Eduardo Motta em seu artigo “O ISEB no banco dos réus” (2000), valendo-se do conceito de "campo intelectual" de Pierre Bourdieu, compreende a postura desta primeira fase crítica ao ISEB como uma luta pela "legitimidade científica/institucional" e pela "posse" do "aparato conceitual marxista":

Compreende-se então que havia entre os isebianos e seus críticos "à esquerda" uma luta pela "classificação do mundo real" (Bourdieu, 1990:167), visto que os críticos ao denegarem um conjunto de obras de inspiração marxista por estas serem "insuficientemente" marxistas ou revolucionárias, estabeleceram uma "linha de demarcação" entre algo que se entendia por ser um "marxismo autêntico" em contraste com um marxismo entendido como "falso" (MOTTA, 2000, p. 137).

Se, por um lado, a delimitação do período do ISEB analisado por esta primeira fase crítica permitiu um aprofundamento e uma densidade analítica sobre o objeto de estudo, por outro, gerou uma incapacidade de analisar as transformações teóricas e políticas da Instituição ao longo de sua existência. As formulações de Toledo e Franco se baseiam, principalmente, na fase desenvolvimentista do ISEB, de 1956 a 1960. Porém, não foi uma escolha voluntária, tratou-se da possibilidade de acesso às fontes, Toledo justifica que não analisou o ISEB em sua última fase, de 1961 a 1964, pois não teve acesso a tais materiais por causa da ditadura empresarial-militar, ou por "razões de Estado", como se refere o autor (TOLEDO, 1977, p. 18).

Para Lovatto, a última fase vai imprimir um caráter antiimperialista ao nacionalismo isebiano (LOVATTO, 2010, p.79); já Daniel Pécaut afirma que o discurso "nacional-desenvolvimentista" do ISEB da década de 50 foi substituído por um discurso "nacional-marxista", influenciado tanto pelos conceitos marxistas como pelos movimentos terceiro-mundistas (PÉCAUT, 1990, p. 106). Portanto, a primeira fase crítica ao ISEB não foi capaz de incluir, com profundidade em suas análises, um período do ISEB radicalizado 
e mais próximo das formulações de cunho revolucionário. Talvez, ironicamente, caíram na mesma natureza da crítica feita por eles a Álvaro Vieira Pinto, de ter sido "parcial" na leitura de Karl Marx: por sua vez, parciais na leitura do Instituto, generalizando a todo o período de existência do ISEB o epíteto de "fábrica" de ideologias.

Em 2005, Caio Navarro de Toledo organizou um livro em ocasião dos 50 anos de fundação do ISEB, intitulado Intelectuais e política no Brasil, a experiência do ISEB. Contou com cinco textos de ex-isebianos e o mesmo número de textos de estudiosos sobre o tema, dos quais, ele está incluído. Percebe-se o impacto da "fase de reabilitação" na concepção desta obra e no próprio texto escrito pelo organizador. 0 espaço destinado aos ex-isebianos na obra é peculiar diante da postura de rejeição aos "nacionalistas" promovida pelos intelectuais uspianos. Houve algumas críticas, presentes nos textos dos antigos membros do Instituto, ao papel da USP frente ao ISEB, umas mais duras, como, por exemplo, a opinião de Joel Rufino dos Santos:

De todo jeito, a questão parece estar no embate ideológico entre o discurso prático (não da prática vulgar, mas da política dos isebianos, da primeira à última fase do instituto, e o discurso sociométrico - uma derivação do velho empirismo-, que pontificou nas escolas paulistas de ciência social, a partir dos anos 50, trazendo consigo a conversa fiada da neutralidade científica (DOS SANTOS, 2005, p.52).

No texto de Caio Navarro de Toledo, vemos algumas mudanças significativas em relação a sua célebre obra da década de 1970. A concepção de ideologia adotada pelo autor já não será mais a de Althusser, o autor passa a adotar a concepção de Nico Poulantzas.

O campo da luta ideológica é um complexo e variado cenário onde se manifesta uma intensa disputa, como também um permanente tráfego simbólico: significados se opõem, mas também são apropriados, trocados, transformados, recuperados e refletidos. Sendo assim, a luta ideológica deixa de ser pensada como a imposição unilateral de crenças, representações, símbolos, valores e interesses de uma classe ou de um grupo social sobre o outro; a luta ideológica se realiza, pois, em um cenário dinâmico onde os discursos e as práticas se relacionam permanente e intensamente (TOLEDO, 2005, p. 141).

Sendo assim, a ideologia formulada pelo ISEB passa a não mais ser compreendida sob a chave de um "falseamento", de uma ferramenta anticientífica, a serviço da classe dominante. Deu lugar a um aparelho ideológico 
que se apresentou enquanto interlocutor e até representativo de setores dominados. A discrepância entre as visões de ISEB depois de mais de trinta anos não são tergiversadas pelo autor, a explicação de Toledo, que serve mais como isenção do que autocrítica, está baseada que a sua análise irá focar no ISEB dos anos sessenta e em sua atuação política, visto que ISEB: Fábrica de ideologias se debruçou nos anos cinquenta e na dimensão teórica da construção do conceito de ideologia do desenvolvimento. Portanto trata-se de dois trabalhos que estancam as fases do ISEB, irresoluto acerca das transformações teóricas e políticas ao longo de toda a trajetória do Instituto, longe de compreender os dilemas e os embates existentes internamente. Nota-se que uma crítica de natureza semelhante é destinada pelo próprio autor aos ex-isebianos críticos da fase "radical" do ISEB - Hélio Jaguaribe e Alberto Guerreiro Ramos -, porém o mesmo não a realiza em forma de autocrítica:

Tais interpretações não deixam de ter um caráter idealizante, pois negam ao ISEB sua diversidade, sua complexidade e sua historicidade. Não se pode negar que a combativa fase do ISEB (...) não deixou de ser resultado de lutas internas - presentes desde a fundação -, como também das contradições sociais e dos dilemas políticos que dividiam a sociedade brasileira. Sem esse entendimento, arruína-se qualquer tentativa de compreender a dinâmica das instituições sociais e dialética dos processos históricos. (TOLEDO, 2005, p.162.)

A inserção do "último" ISEB em uma posição "progressista" no contexto do pré-1964 evidencia o impacto da "fase de reabilitação" sobre a visão do autor. Toledo irá realizar uma análise comparativa da atuação do ISEB e do Instituto de Pesquisa e Estudo Sociais (IPES), organização da sociedade civil fundada em 1961 que tinha como objetivo levar a cabo uma "modernização conservadora" que desembocou no golpe empresarial-militar de 19648, colocando-os em posições opostas na luta ideológica do período. "Pode-se afirmar que o IPES tinha o "último ISEB" como seu inimigo declarado." (TOLEDO, 2005, p.152). Porém, o reconhecimento da importância do ISEB na

\footnotetext{
${ }^{8}$ Caio Navarro de Toledo se utiliza da profunda pesquisa do historiador Renè Dreifuss sobre a atuação do IPES em sua obra 1964: a conquista do Estado - Ação política, poder e golpe de classe, na qual, sugestiona o IPES enquanto um Instituto "anti-ISEB".
} 
história será mais no campo de sua atuação política do que de sua formulação teórica: “Hoje, o ISEB - apesar de seus equívocos teóricos, políticos e ideológicos - deve ser lembrado como uma instituição cultural cujos intelectuais se comprometeram com a defesa de causas progressistas e de caráter democrático." (TOLEDO, 2005, p. 162-163).

Fora do centro intelectual formulador de críticas ao ISEB, a USP, mas dentro deste período marcado por duras críticas ao Instituto, Alzira Abreu realizou na França um dos primeiros estudos sobre o Instituto com a sua tese de doutorado intitulada Nationalisme et Action Politique au Brésil: une étude sur l'ISEB (1975). Sem carregar nas tintas do escopo da crítica paulista que associava o nacionalismo ao escamoteamento da luta de classes e manipulação, Abreu focou na análise da atuação política do ISEB, seu modus operandi e suas estratégias. Dividindo em dois momentos a forma de atuação do Instituto, a autora irá defini-lo enquanto um "grupo de interesses". A atuação isebiana durante a década de 1950 tinha como tônica a persuasão, através de cursos e seminários.

Com o malogro de aceder e influenciar o Estado através do "convencimento", passou-se a atuar enquanto um "grupo de pressão", se aproximando de movimentos populares, de cultura, etc. Vale a pena destrincharmos essa tese da historiadora Alzira Abreu. Apesar da autora chegar a identificar a pretensão isebiana de atuar enquanto uma "assessoria" do governo federal, é interessante notarmos que, ao apontar o insucesso da persuasão, tal estudo se afasta da ideia de que as formulações isebianas foram responsáveis pelas políticas de industrialização e desenvolvimento realizadas no período.

Dois argumentos são dados pela autora para o ocorrido, o primeiro trata-se da mudança do perfil dos intelectuais que passaram a ter legitimidade frente ao Estado, de formação jurídica com um olhar mais amplo da sociedade para uma formação mais econômica como uma visão tecnocrática. Portanto, o acesso à dimensão mais técnica da economia afastou os cientistas sociais e políticos dos aparelhos do Estado e do poder de decisão. Tal assertiva merece uma relativização, trata-se de difícil aceitação, 
após lermos, por exemplo, os escritos de Hélio Jaguaribe, como "Para uma política nacional de desenvolvimento", de 1956, o questionamento de sua "capacidade técnica" na área econômica. Torna-se mais interessante se deslocarmos essa questão da "capacidade técnica" para a política. Ou seja, o interesse da classe dominante por um modelo de desenvolvimento com a abertura para o capital estrangeiro formou e, ao mesmo tempo, inseriu intelectuais com o pensamento econômico correlato no poder executivo.

Outro argumento da autora para o descalabro isebiano na década de 1950 trata-se de um descompasso entre o momento das formulações isebianas e a etapa de desenvolvimento do capitalismo brasileiro. "A oportunidade de uma alternativa nacionalista parecia não mais existir quando o ISEB se organizou e iniciou e suas atividades." (ABREU, 2005, p. 105). Próximos a essa compreensão da autora, aderimos à tese da organização "tardia" do ISEB:

Houve a organização "tardia" de intelectuais nacionalistas em um contexto de crescente integração do Brasil ao sistema capitalista. As formulações de projetos nacionalistas deram a tônica no campo intelectual dos anos 50 ao passo que a abertura ao capital estrangeiro era a nota forte no campo econômico (MULLER, 2019, p.92).

Em relação à transição no modo de atuar do ISEB, de um grupo de persuasão para um grupo de pressão, levando-o a sua radicalização, torna-se relevante analisarmos as mudanças do Instituto para além do anseio isebiano de interferir no Estado em prol de um desenvolvimento nacionalista, mais além das táticas adotadas, temos que levar em consideração as próprias mudanças ideológicas ocorridas no interior do ISEB, e o papel político dado às distintas classes sociais no processo de transformação nacional. As mudanças na concepção de ideologia do desenvolvimento dentro do Instituto foi um determinante para as alterações nas práticas políticas do mesmo. Mais à frente abordaremos brevemente como que as distinções entre os conceitos de ideologia formulados por Hélio Jaguaribe e Álvaro Vieira Pinto têm relação com a atuação política do ISEB. 


\section{A fase da reabilitação: os pensadores do "nacionalismo"}

As primeiras obras que trouxeram reflexões alternativas às produções da fase crítica do ISEB não tardaram a chegar. Ainda, em um período de forte influência da sociologia paulista sobre o tema, Renato Ortiz, na obra Cultura Brasileira e Identidade Nacional (1984) inaugura, com maiores repercussões, uma série de produções que vêm a seguir e que trabalham com perspectivas de análise diversas à primeira fase crítica.

Seguido de Daniel Pécaut, com a obra Os intelectuais e a política no Brasil: entre o povo e a nação (1990). Luiz Eduardo Motta irá produzir o artigo "O ISEB no banco dos reús" (2000) com críticas mais agudas aos estudiosos "de primeira hora", já fortemente referenciado nas obras de Ortiz e Pécaut. Angélica Lovatto, ao escrever sua tese de doutorado "Os Cadernos do Povo brasileiro e o debate nacionalista nos anos 1960: um projeto de revolução brasileira" (2010), com o recorte temporal voltado para a última fase do ISEB, irá se distanciar das análises críticas da década de 1970 sobre o Instituto.

Uma primeira característica desta fase da sociologia sobre o ISEB é que todos esses autores citados estabeleceram um diálogo com a primeira fase crítica, principalmente com o clássico ISEB: Fábrica de Ideologias, e produziram uma perspectiva alternativa, quando não em oposição, sobre o ISEB. Todavia, ao contrário dos primeiros críticos, os intelectuais da segunda fase não compartilham, necessariamente, das mesmas influências teóricas e possuem interesses em dimensões variadas do Instituto. Tal fato se explica por partirem de lugares diversos de produção intelectual ${ }^{9}$, ao contrário da primeira fase que partiu de um centro intelectual específico, a USP. A respeito das visões serem "alternativas" à primeira fase, o contexto político, a partir da redemocratização na década de 80 , torna-se importante fator explicativo. Com a volta de bandeiras políticas identificadas com o nacionalismo desde a

\footnotetext{
9 Ortiz tem formação acadêmica na França, era docente da UFMG quando escreveu sua referida obra, influenciada pelos debates realizados na ANPOCS. Pécaut fez sua carreira acadêmica na França e se tornou um "latino-americanista". Motta se formou nas Ciências Sociais da UFRJ e tornou-se docente da mesma instituição. Lovatto tem a sua formação de cientista social na PUC-SP.
} 
perspectiva da esquerda e a reorganização dos movimentos sociais que operavam narrativas que envolviam conceitos como "povo" e "nação", as ciências sociais passaram a estudar a categoria de "nação", suas derivações e seus operadores, com base em novos pressupostos teóricos - no caso do ISEB ocorre um deslizamento dos debates/conceitos de "ideologia" para "nacionalismo".

Renato Ortiz irá analisar o ISEB sob o viés da cultura: "O objetivo deste livro é retomar as diferentes maneiras como a identidade nacional e a cultura brasileira foram consideradas." (ORTIZ, 1994, p. 8). Portanto, o capítulo que coube ao Instituto, nomeado "Alienação e cultura: o ISEB" faz parte de um esforço maior de pensar a pluralidade das identidades nacionais em diferentes momentos históricos, a partir de suas reinterpretações do "popular" pelos grupos sociais e através da construção do Estado brasileiro. 0 autor inicia a sua obra indicando o tratamento da cultura para o ISEB dentro de um projeto a ser realizado, ou seja, "um vir a ser", ao tratá-la como instrumento de transformação da comunidade. Sendo assim, os isebianos se distanciam da intelectualidade do passado ao operar o tema com a perspectiva futura. Ortiz destaca uma série de conceitos do campo da cultura que foram forjados pela Instituição e que se tornaram recorrentemente utilizados.

Quando (...) deparamos com conceitos como "cultura alienada", "colonialismo" ou "autenticidade cultural", agimos com uma naturalidade espantosa, esquecendo-nos de que eles foram (...) produzidos pela intelligentsia do ISEB. Penso que não seria exagero considerar o ISEB como matriz de um tipo de pensamento que baliza a discussão da questão cultural no Brasil dos anos 60 até hoje (ORTIZ, 1994, p. 46).

Portanto, o ângulo de análise do autor sobre o ISEB se diferencia da primeira fase crítica, pois não está preocupado em analisar a produção teórica do Instituto em si, mas a sua recepção e impacto no meio social.

Incluindo Daniel Pécaut neste debate, o sociólogo francês em sua obra Os intelectuais e a política no Brasil: entre o povo e a nação irá analisar a intelectualidade brasileira de 1920 até 1982. Pécaut vai ao encontro da perspectiva de Ortiz, por se abster de realizar uma reflexão sobre o local do intelectual na sociedade sem antes partir para o reconhecimento deste e de 
sua produção numa determinada época e determinado meio social. Logo, a dimensão da "ação política" dos intelectuais será sensível a Pécaut: "Os intelectuais brasileiros se entregam à ação política sem nenhuma hesitação e como se tivessem qualificação especial para fazê-lo." (PÉCAUT, 1990, p. 7.). Sendo assim, a fase de reabilitação do ISEB parte de perspectivas analíticas diferentes da primeira e chegará a uma conclusão distinta sobre o Instituto: não se tratava de um "aparelho ideológico" a serviço da hegemonia da classe dominante. Identifico e destaco dois argumentos fortes que norteiam essa tese.

0 primeiro argumento diz respeito ao fato de que as formulações isebianas não foram implementadas pelo Estado brasileiro, pelo contrário, as políticas de Estado, muitas vezes, caminharam em oposição às desenvolvidas pelo ISEB. Ortiz aponta que o ISEB não se tornou uma "fábrica de ideologias" do governo Kubitschek. Como indica o sociólogo, o Governo JK realizou uma abertura da economia brasileira ao capital estrangeiro enquanto os isebianos procuraram produzir um "ideário nacionalista para se diagnosticar e agir sobre os problemas nacionais." (ORTIZ, 1994, p. 47).

Se de fato o Estado desenvolvimentista procurou uma legitimação ideológica junto a um determinado grupo de intelectuais, não é menos verdade que os avatares desta ideologia caminharam em um sentido oposto ao do Estado brasileiro. (ORTIZ, 1994, p.46).

Daniel Pécaut retira os isebianos de um local incólume aos debates e disputas políticas da sociedade, por causa de um suposto poder estatal, longe de estarem em uma "torre de marfim", como escreve alegoricamente o sociólogo francês.

Os isebianos também não estavam acima das disputas, mesmo quando falavam em nome de toda a nação; estavam presos às cisões que dividiam tanto as elites quanto as classes médias. E não há dúvida de que se situavam do lado das "forças progressistas", sendo assim percebidas tanto por seus aliados como por seus adversários (PÉCAUT, 1990, p.124).

O Instituto Superior de Estudos Brasileiros era, de fato, ligado ao Estado brasileiro, mais especificamente ao Ministério da Educação. Como afirma Hélio Jaguaribe em 2005, citado por Angélica Lovatto (2010, pp. 72-73) em sua tese, o projeto inicial elaborado por ele previa o Instituto enquanto um 
estabelecimento de ensino em nível nacional e de publicações das produções intelectuais. Todavia, pelo contexto político conturbado dos anos de 1954-55 e a falta de verba, prevaleceu apenas a dimensão mais editorial do Instituto, e a respeito do ensino se reduziu às conferências e cursos anuais ${ }^{10}$. Já na última fase, o ISEB sofreu com a falta de verbas estatais ${ }^{11}$. Torna-se claro que a existência do Instituto no âmbito do Estado nunca foi vista como uma prioridade pelos governos federais, sendo o seu funcionamento muito mais um esforço de seus intelectuais do que uma vontade política do governo central. E se formos retornar à gênese do ISEB, o IBESP foi idealizado e financiado pelo próprio Hélio Jaguaribe e outros intelectuais ${ }^{12}$.

Tal fato corrobora com a tese dos autores desta segunda fase que refutam o Instituto enquanto um aparelho da classe dominante. A respeito da relação entre o ISEB e as políticas de Estado, estabeleceu-se um consenso na atual fase das Ciências Sociais sobre a Instituição, uma vez que nos anos de 1956 a 1960, como afirmou Ortiz, a relação era de negligência por parte do Estado, e na fase de 1961 a 1964, o Instituto passou a apoiar as Reformas de Base encampadas pelo Governo João Goulart. Reduzir o Instituto à sua relação com o Estado trata-se de negligenciar toda a sua penetração na sociedade civil e nas classes sociais. Como afirma Pècaut: "ISEB era muito mais do que um simples meio para um grupo de intelectuais se situar na órbita do poder." (PÉCAUT, 1990, 130).

0 segundo argumento diz respeito à ideologia produzida pelo ISEB, indicando que ela não serviu em prol da hegemonia da classe dominante. Ortiz concorda com a tese da primeira fase que afirma que a centralidade da nação no conceito de alienação "encoberta" a luta de classes, porém se

\footnotetext{
10 "o último ISEB estava - nos idos de 1962 - completamente sem verbas do Estado, como parte de uma estratégia que resultasse no isolamento e gradativa perda de espaço e influência isebiana." (LOVATTO, 2010, p. 66).

11 "O IBESP foi criado em 1954, sob a direção de Hélio Jaguaribe. O Instituto sobrevivia de pequenas contribuições de seus próprios membros. Chegou a publicar cinco números da Revista Cadernos do nosso tempo, financiada exclusivamente por Hélio Jaguaribe, com parte dos proventos de sua atividade como advogado." (LOVATTO, 2010, p. 72).

12 Tais pressupostos de Álvaro Vieira Pinto estão presentes em suas obras Ideologia e Desenvolvimento Nacional e Consciência e Realidade Nacional. Também está presente na análise de Caio Navarro de Toledo em ISEB: Fábricas de Ideologias (2005, pp. 43-44).
} 
distancia de qualificá-la enquanto instrumento da classe dominante sob o argumento de que tais ideias não seguiram o curso da "oficialidade", ou seja, do Estado, "mas encontrou um caminho de popularização que ganhou pouco a pouco terreno junto a setores progressistas e de esquerda." (ORTIZ, 1994, p. 47). Será neste sentido, que o autor se refere à transição da primeira para a segunda fase do ISEB. Inclusive, para o sociólogo, a atualidade de ISEB reside neste curso popular de suas ideias, onde uma série de conceitos isebianos foi internalizada e compartilhada.

Refiro-me ao Movimento de Cultura Popular no Recife e ao CPC da UNE. Se tomarmos, a título de referência, dois intelectuais proeminentes desses movimentos, Paulo Freire e Carlos Estevam Martins, observamos que as relações com o ISEB são substanciais. (...) A teoria isebiana, ou pelo menos parte dela, penetra tanto as forças de esquerda marxista quanto o pensamento social católico (ORTIZ, 1994, p. 48)

Logo, Ortiz não somente descarta o curso das ideias isebianas enquanto "conservadoras", como as qualifica enquanto influenciadoras no campo "progressista" da época. Daniel Pécaut, compartilhando da visão do antropólogo sobre a função da ideologia isebiana, irá apontar que esta transição de um "nacional-desenvolvimentismo" para um "nacionalmarxismo" não representa uma ruptura com os ideais de desenvolvimento, pelo contrário, trata-se do seu alargamento sob influência de um contexto do Terceiro Mundo. Talvez a maior ruptura resida na postura intelectual diante da política (em seu sentido amplo). Como aponta Pécaut: "No final dos anos 50, a palavra de ordem foi a adesão voluntária dos intelectuais às causas populares." (PÉCAUT, 1990, p.5).

Identificamos um possível deslocamento do ISEB do predominante conceito de ideologia de Hélio Jaguaribe para o de Álvaro Vieira Pinto durante a passagem de fases. Enquanto na década de 50, a ideologia "autêntica" de Hélio Jaguaribe, transversal a todos os setores "modernos" das classes, dava a tônica da fase nacional-desenvolvimentista, no início da década de 60, a categoria de ideologia de Álvaro Vieira Pinto ganhou força. Vieira Pinto defende que as "massas" são as únicas capazes de desenvolver a ideologia autêntica (do desenvolvimento). Isso não significa que as ideologias das demais classes não sejam autênticas no sentido de apontar para a evolução 
da nação, porém elas devem proceder da consciência das massas. 0 filósofo explica teoricamente tal assertiva através do conceito de "trabalho". Sinteticamente, tal conceito aponta que somente através do trabalho se dá o acesso à realidade ${ }^{13}$. Portanto, a operação política da ideologia "autêntica" de Álvaro Vieira levaria a uma aproximação do Instituto com as camadas populares, o que de fato ocorre em sua última fase.

Para explicar a função da ideologia isebiana dentro do campo "progressista", os autores desta fase da reabilitação do ISEB fazem comumente duas correspondências: ao contexto interno, da relação do Instituto com forças políticas progressistas, o CPC da UNE, Ligas Camponesas, etc; e ao contexto externo, do pensamento político e teórico em comum dos chamados movimentos de libertação do Terceiro Mundo.

A tese de doutorado de Angélica Lovatto, a partir da análise dos Cadernos do Povo Brasileiro, produzidos pelo ISEB de 1962 a 1964, tem como objetivo compreender o caráter político da referida produção isebiana e precisar a sua função social no contexto político da época.

Desta forma, trata-se de um bom exemplo da correspondência entre o Instituto e as forças políticas internas, citada no parágrafo anterior. A principal referência teórica de Lovatto para compreender a produção ideológica do ISEB será Giorgio Lukács, bem distinta das influências althuserianas da primeira fase crítica ao ISEB. Lovatto apresenta as principais características do pensamento lukacsiano sobre a categoria de ideologia. $\mathrm{O}$ filósofo húngaro ao invés de entender a ideologia enquanto um "falseamento da realidade" compreenderá através de sua "função social", através de três operações analíticas de uma determinada ideologia: a "análise imanente", a "gênese" e, por fim, a "função social". A análise imanente consiste em revelar as características genuínas e originais de um determinado discurso, e não qualidades que lhe são atribuídas. A gênese é o

\footnotetext{
${ }^{13}$ Sobre os Cadernos do Povo Brasileiro: "Os Cadernos do povo brasileiro foram editados pela Civilização Brasileira, no Rio de Janeiro, sob a coordenação de Ênio Silveira, figura emblemática da propagação da cultura brasileira antes e depois da ditadura militar. Os diretores dessa coleção eram o próprio Silveira e Álvaro Vieira Pinto, este último pertencente aos quadros do ISEB - Instituto Superior de Estudos Brasileiros (1955-64) (LOVATTO, 2010, p. 20).
} 
meio concreto, os "liames sociais", de onde a ideia parte. E, por fim, a função social, ou seja, a ideia enquanto veículo de conscientização da prática dos homens (LOVATTO, 2010, p. 44). Neste sentido, a autora deu um tratamento teórico-analítico à ideologia produzida pelo ISEB completamente distinto do realizado pela sociologia uspiana na década de $70^{14}$. A sua conclusão é que o ISEB, mais especificamente na dimensão dos Cadernos do povo brasileiro, cumpriu um papel de divulgador de conhecimento histórico no Brasil, visto o teor de sua coletânea, e desempenhou importante agitação e propaganda na luta de classes. "Prova disso foi a discussão que suscitaram a partir da inserção da publicação nos sindicatos, nas fábricas, nas Ligas, na UNE, no CPC, no CGT, nos partidos, nas universidades, etc." (LOVATTO, 2010, p. 353). A autora ressalta que a despeito de uma possível inconsistência teórica presente nos Cadernos, o resultado foi a contribuição "para o processo de tomada de posição e consciência das contradições das lutas de classe" (LOVATTO, 2010, p.353). Sendo assim, não se tratou apenas de um instrumento de agitação e propaganda. Lovatto coloca à prova a eficácia da função social dos Cadernos através da "reação dos setores conservadores da sociedade à publicação." (LOVATTO, 2010, p. 354), citando o ISEB enquanto alvo imediato do golpe de 1964. Dissertar sobre a queda do Instituto por parte dos militares tornou-se um argumento forte e recorrentemente utilizado por esta fase da reabilitação do ISEB. Ortiz também cita: “0 golpe de 64 erradicou qualquer pretensão de oficialidade das teorias do ISEB" (ORTIZ, 1994, pág. 44). Lovatto irá definir o caráter político dos Cadernos do povo brasileiro enquanto uma "estratégia etapista da revolução democrática-

\footnotetext{
14 Celso Frederico em artigo que trata da recepção de Lukács no Brasil aborda, em certa altura, a relação da USP com o filósofo Húngaro: "O projeto intelectual uspiano, entretanto, estava inteiramente voltado para a justificação da sociologia como uma ciência autônoma, dotada de um objeto e de um método próprios. A filiação positivista deste projeto é clara. (...) A formação do arsenal teórico da sociologia praticada inicialmente na USP incluía Durkheim, Weber, Marx e o estruturo-funcionalismo americano. Marx, assim, era um autor importante citado elogiosamente como "um clássico da sociologia alemã", e não como o criador do materialismo histórico. Lukács surge como um pensador inconveniente que inviabiliza qualquer tentativa de se glorificar a "natureza sociológica da sociologia", ao denunciar o pressuposto conservador dessa empreitada (...)" (FREDERICO, 2019).
} 
burguesa", na qual apontava uma luta de características mais democráticas do que socialistas.

Por sua vez, a obra de Renato Ortiz e o artigo de Luiz Eduardo Motta são exemplos da correspondência entre o ISEB e os movimentos terceiromundistas. Ortiz afirmará que “(...) chama a atenção nos escritos de Fanon e do ISEB é que ambos se estruturam a partir dos mesmos conceitos fundamentais: o de alienação e o de situação colonial" (ORTIZ, 1994, p. 50). Apesar de descartar um conhecimento dos isebianos por parte de Fanon, o interessante para Renato Ortiz consiste nas correspondências de tais intelectuais a um contexto de Terceiro Mundo. 0 antropólogo aponta que tanto Fanon quanto Vieira Pinto foram fortemente influenciados pelos estudos de Balandier e Sartre sobre a situação colonial.

A originalidade de Balandier consiste em apreender o colonialismo enquanto um fenômeno social total. (...) procura entender os aspectos da dominação colonialista, seja no nível do imperialismo econômico seja em suas manifestações mais profundas que engendram a própria personalidade do homem colonizado (ORTIZ, 1994, pp. 52-53).

Porém, aponta Ortiz, Balandier estava preocupado, no âmbito dos estudos, como a sociologia poderia "retirar ensinamentos" sobre o colonialismo, enquanto Sartre tem como foco a desmistificação de uma moral colonialista, sendo assim, a "alienação do colonizador" torna-se o tema de combate deste existencialista francês. Já as perspectivas dos intelectuais do Terceiro Mundo, influenciados pelo existencialismo, serão outras. "Os intelectuais do mundo periférico falarão pelo "outro lado", seja de uma forma reformista como ISEB ou revolucionária como Fanon.” (ORTIZ, 1994, p. 53). Ortiz aponta que as categorias de situação colonial e alienação serão manuseadas por Fanon e os isebianos em uma perspectiva de libertação da dominação colonial. 0 existencialismo francês, portanto, é transportado à realidade objetiva dos intelectuais periféricos e pensado a partir da categoria de "nação", ausente das formulações francesas. Sendo assim, a proposta de leitura da realidade racial, e mais tarde nacional, por parte de Fanon e também nacional por parte dos isebianos, revela a necessidade da busca por uma "consciência autêntica". Ortiz cita Roland Corbisier: "A tomada de 
consciência de um país por ele próprio não ocorre arbitrariamente, mas é um fenômeno histórico que implica e assinala a ruptura do complexo colonial" (CORBISIER apud ORTIZ, 1994, p. 55). Sendo assim, dentro da realidade colonial, surge um movimento de tentativa de sua superação, na qual a nação e a sua "essência" estão alienadas e todos que nela vivem têm a sua dimensão humana tolhida. Referindo-se à luta de libertação argelina, Fanon escreve:

A nação argelina não está mais no céu futuro. Ela não é mais o produto da imaginação nebulosa ou dos fantasmas enrijecidos. Ela está no centro do novo homem argelino. Existe uma nova natureza do homem argelino, uma nova dimensão de sua existência. (FANON apud ORTIZ, 1994, p. 60).

Luiz Eduardo Motta destaca a importância das correspondências feitas por Ortiz, pois insere o ISEB num contexto mais amplo, que ia além de reproduzir ideologias "burguesas" no interior da sociedade brasileira, se inserindo numa trincheira de luta anticolonial através de seu caráter nacionalista:

Essa observação de Renato Ortiz é importante porque insere a obra isebiana num contexto global. Com efeito, o nacionalismo isebiano se inseria num processo amplo e não restrito à nossa formação social, o que nos leva a perceber que os trabalhos do ISEB, mais do que reproduzir uma ideologia localizada num aparelho de Estado para fomentar a hegemonia burguesa, expressava uma concepção de mundo que correspondia aos valores e questões daquela época (MOTTA, 2001, pp. 131-32).

Portanto, o "nacionalismo" e/ou a "ideologia nacional" se tornam uma das categorias centrais nos estudos dos autores desta fase da reabilitação do ISEB, sendo limitadora ou ampliadora da ação política dos isebianos. Para Ortiz e Motta, o nacionalismo filia esta última fase do ISEB em um movimento mais amplo terceiro-mundista. Motta vai além, definindo enquanto um "nacionalismo revolucionário" que lhe "abriu portas" com a esquerda no país. "E foi esse segundo tipo de nacionalismo - o revolucionário da última fase do ISEB que obteve grande receptividade nos movimentos da esquerda engajada" (MOTTA, 2001, 135). Motta parte de um referencial teórico sobre nacionalismo do sociólogo argentino Ernesto Laclau que "considerado em si não tem nenhuma conotação classista" (LACLAU, 1979, p. 176).

[...] Laclau não reduz os conceitos de populismo e de nacionalismo a uma ótica classista e, além disso, percebe que a ideologia nacional-populista pode fomentar uma visão crítica e revolucionária aos setores dominados pelo 
grande capital. Para o sociólogo argentino, o nacionalismo não pode ser entendido como uma ideologia feudal, burguesa ou proletária (MOTTA, 2001, p. 130).

Por outro lado, Angélica Lovatto aponta que o nacionalismo do ISEB, em sua última fase, expressados nos Cadernos do povo brasileiro, estava predominantemente relacionado à luta de cunho democrática, e não, diretamente, socialista:

[...] prevaleceu um nacionalismo apresentado como uma luta do povo, no sentido de uma luta democrático-popular acreditando que uma fração da burguesia nacional pudesse estar efetivamente interessada mais na autonomia de seu desenvolvimento do que em se aliar ao imperialismo e ao latifúndio (LOVATTO, 2010, p. 355).

Portanto, conclui Lovatto, as formulações para uma "revolução brasileira" foram condicionadas aos limites da "apropriação dos elementos progressistas da ideologia burguesa pelo proletariado" (LOVATTO, 2010, p. 356), pois, para a autora, a ideologia nacional limitaria a luta dos trabalhadores ao território nacional. A influência teórica da autora sobre o tema do nacionalismo parte do seu próprio orientador, o cientista político Lúcio Flávio Rodrigues de Almeida:

[...] a ideologia nacional é um modo específico de assegurar as condições de reprodução do capitalismo, ao mesmo tempo em que encontra nesse tipo de sociedade um terreno adequado à sua própria reprodução; 2) [...]a ideologia nacional se atualiza por intermédio das lutas das diferentes classes sociais e frações de classe, ou seja, por um lado a apreensão do movimento contraditório da ideologia nacional no bojo de distintas apropriações sociais e, por outro, a compreensão de maneira mais precisa do nacionalismo (ALMEIDA apud LOVATTO, 2010, p. 170).

Por fim, cada um dos autores refuta, a sua maneira, a tese de que os isebianos operavam equivocadamente as categorias sociológicas. Ortiz afirma que seria difícil entender a hegemonia de um pensamento que se enraíza na esquerda brasileira sendo a base deste uma "leitura sem rigor". 0 exemplo da leitura hegeliana por parte dos isebianos evidencia, para Ortiz, o domínio de tais intelectuais sobre as categorias sociológicas, neste caso, o idealismo. Em resposta indireta a Caio Navarro de Toledo, Ortiz considera a interpretação isebiana da "dialética do Senhor e do Escravo" de Hegel como 
uma passagem do pensamento hegeliano do terreno filosófico para o político, porém não se trata, por isso, de uma interpretação equivocada:

A identificação do senhor ao colonizador e do escravo ao colonizado é certamente ideológica, mas permite aos pensadores periféricos se situarem do lado da História, e possibilita a articulação de um discurso político que se insurge contra a dominação capitalista (ORTIZ, 1994, p. 59).

Luiz Eduardo Motta refuta a crítica negativa de que os isebianos teriam feito um "coquetel filosófico" envolvendo o marxismo. Para o cientista político, as diversas correspondências de categorias provindas de filiações teóricas distintas enriquecem o pensamento teórico e não são exclusividades do ISEB:

No campo teórico, a contribuição e a riqueza do marxismo ocidental é enorme devido à aproximação dos vários intelectuais identificados com essa corrente com outras perspectivas teóricas não marxistas, a exemplo de Lukács, da Escola de Frankfurt e de Della Volpe em relação à sociologia de Max Weber; de Gramsci com o historicismo de Benedetto Croce e o realismo político de Maquiavel e dos elitistas italianos; de Althusser com o estruturalismo francês [...] (MOTTA, 2001, p. 138).

Angélica Lovatto também irá rejeitar as críticas de imprecisão teórica com motivações ideológicas aos Cadernos, longe de considerá-los um primor teórico, porém, a autora está preocupada, como já foi exposto, com a função ideológica desenvolvida pelos Cadernos, mais do que um "rigor científico" acadêmico:

Portanto, de fato contestamos aqueles que consideram os Cadernos do povo brasileiro apenas como uma mera agitação e propaganda de baixo nível, com estilo pedagógico autoritário, de caráter histórico-panfletário e resultado político-manipulatório. Já pudemos deixar claro que não consideramos a coleção o supra-sumo do conhecimento científico, nem a versão mais acabada das propostas nacionalistas do período (LOVATTO, 2010, p. 363).

\section{Conclusão}

Assim, os debates das Ciências Sociais sobre o ISEB apresentam um longo e tortuoso trajeto nos últimos 45 anos, sedimentado por críticas ao Instituto, sua reabilitação e, principalmente, de variados debates entre os autores que se debruçaram sobre este grupo de intelectuais. Podemos concluir que na trajetória desta sociologia identificamos duas fases: 
1) A fase crítica, na década de 70, promovida por intelectuais uspianos (TOLEDO, 1974; FRANCO, 1976; por exemplo), marcada por críticas às "imprecisões teóricas" dos isebianos, relacionando-as a uma produção ideológica que escamoteava a luta de classes e conferindo-lhes um status de aparelho ideológico da classe dominante. 0 eixo central de tais análises gira ao entorno da categoria de ideologia;

2) A fase da reabilitação, com obras espaçadas de meados dos anos 80 até a primeira década do século XXI, com um local de escrita difuso por intelectuais leitores das primeiras críticas ao Instituto (ORTIZ, 1985; PÉCAUT, 1990; MOTTA, 2000; LOVATTO, 2010; por exemplo), privilegia uma análise que relaciona o Instituto ao contexto político do Brasil e/ou dos países de do chamado Terceiro Mundo, a partir daí conferindo-lhe uma função política importante com um determinado lugar no "campo progressista", incluindo as transformações teóricas e políticas ocorridas na transição de fases do ISEB. A categoria de "nacionalismo" torna-se uma referência importante para esta fase.

Tais fases não são nitidamente demarcadas através de uma ruptura entre a "crítica" e a "reabilitação", não se trata de dois momentos estanques de críticas "contra" e depois "pró" ISEB em sua totalidade. Descartada essa visão pueril, auferimos ambas as fases como uma maneira de melhor compreender as Ciências Sociais sobre o ISEB ao longo das últimas cinco décadas. Em decorrência da variedade de temas estudados pela Instituição, a heterogeneidade de ideias, o grande número de intelectuais mobilizados e o seu tempo de existência, torna-se de difícil tarefa estabelecer uma análise do Instituto que seja unívoca e hegemônica.

Se é verdade que houve perspectivas hegemônicas na década de 70 e início de 80, por outro lado, o panorama que se constitui a partir da metade da década de 80, apesar de "reabilitar" o Instituto no cenário intelectual e político, foi de análises críticas diversas e, às vezes, conflitantes a respeito do 
ISEB, que ora se chocam e ora trilham a mesma direção. Longe de apontar uma visão única sobre tal objeto de estudo, os estudos sobre o Instituto se aproximam muito mais de um labirinto de múltiplas saídas, porém, com trajetos complexos, do que de um caminho bem direcionado, com um destino específico.

\section{Referências}

BOBBIO, Norberto; MATTEUCCI, Nicola; PASQUINO, Gianfranco. Dicionário de política. Brasília: Editora Universidade de Brasília, 1994.

FANON, F. Os condenados da terra. Rio de Janeiro, RJ: Civilização Brasileira, 1979.

FERNANDES, F. A sociologia no Brasil. Rio de Janeiro, RJ: Guanabara,1987.

FRANCO, Maria Sílvia de Carvalho. 0 tempo das ilusões. In: Ideologia e mobilização popular. São Paulo, SP: CEDEC/Paz e Terra, 1985.

FREDERICO, Celso. A recepção de Lukács no Brasil. Disponível em: blogdaboitempo.com.br. Acessado em 22/01/2019.

GUIMARÃES, César. Vargas e Kubitschek: a longa distância entre a Petrobrás e Brasília. In: CARVALHO, Maria Alice Rezende (org.). República no Catete. Rio de Janeiro: Museu da República. 2001.

GOMES, Ângela de Castro. A invenção do Trabalhismo. Rio de Janeiro: Ed. FGV. 2005.

GOMES, Ângela de Castro. 0 populismo e as ciências sociais: notas sobre a trajetória de um conceito. Revista Tempo, Rio de Janeiro, vol. 1, nº. 2, 1996.

HOLLANDA, Cristina Buarque de. Os Cadernos do Nosso Tempo e o Interesse Nacional. DADOS - Revista de Ciências Sociais, Rio de Janeiro, vol. 55, no 3 , 2012.

INSTITUTO BRASILEIRO DE ECONOMIA, SOCIOLOGIA E POLÍTICA (IBESP). Para uma política nacional de desenvolvimento. In: SCHWARTZMAN, Simon (sel. e introd.). 0 pensamento nacionalista e os "Cadernos de Nosso Tempo”. Brasília: UNB/Câmara dos Deputados, 1981. Pág.171-273.

LACLAU, Ernesto. A razão populista. São Paulo: Ed. Três Estrelas. 2013.

LAMOUNIER, Bolívar. O ISEB: notas à margem de um debate. Ed. Discursos, São Paulo. 1979. 
LOVATTO, Angélica. Os Cadernos do Povo brasileiro e o debate nacionalista nos anos 1960: um projeto de revolução brasileira. Tese de Doutorado. PUC-SP. 2010.

LOVATTO, Angélica. A utopia nacionalista de Hélio Jaguaribe - os tempos do ISEB. Revista Lutas Sociais, nº 3, S.Paulo: Xamã. Publicação do NEILS. 1997.

MANNHEIN, Karl. Ideologia e Utopia. Introdução à Sociologia do Conhecimento. Zahar Editores, 1976.

MARX, Karl. Manuscritos econômico-filosóficos. Editora Boitempo (1ํㅡㄹ. ed.), 2004.

MENDONÇA. Sônia Regina. Estado e Economia no Brasil: Opções de Desenvolvimento. Editora Graal. 1999.

MICELI, S. Por uma sociologia das Ciências Sociais. In: História das Ciências Sociais. São Paulo, SP: Vértice, 1989.

MOTTA, Luiz Eduardo. 0 Iseb no banco dos réus. Comum - Rio de Janeiro v.5 - no 15 - ago/dez 2000. p. 119 a 145.

MYERS, Jorge. Músicas distantes. Algumas notas sobre história intelectual hoje: horizontes velhos e novos, perspectivas que se abrem. In: NORONHA, Maria Elisa (org). História intelectual latino-americana: itinerários, debates e perspectivas. Rio de Janeiro: Ed. PUC-Rio, 2016.

MULLER, Hélio Jaguaribe. Pensamento político em tempos isebianos: populismo, desenvolvimento nacional e nacionalismo (1952-1958). 2019. 113 f. Dissertação (Mestrado em História) - Instituto de Filosofia e Ciências Humanas, Universidade do Estado do Rio de Janeiro, Rio de Janeiro, 2019.

ORTIZ, R. Cultura brasileira e identidade nacional. São Paulo, SP: Brasiliense, 1994.

PALTI, Elias. La nueva historia intelectual y sus repercusiones em América Latina. Revista História Unisinos. Vol. 11 № 3 - setembro/dezembro de 2007.

PÉCAUT, D. Os intelectuais e a política no Brasil. São Paulo, SP: Ática, 1990.

PERICÁS, Luis Bernardo; SECCO, Lincoln (orgs). Intérpretes do Brasil: clássicos, rebeldes e renegados. São Paulo: Boitempo, 2014.

PINTO, A. V. Consciência e realidade nacional, 2 vols. Rio de Janeiro, RJ: ISEB,1960. 
PINTO, Álvaro. Ideologia do desenvolvimento nacional. $4^{\underline{a}}$ ed. Rio de Janeiro: ISEB, 1960.

SODRÉ, Nelson Werneck. A Verdade sobre o ISEB. Rio de Janeiro, Avenir Editora. 1978.

TOLEDO, Caio Navarro. ISEB: Fábrica de Ideologias. São Paulo: Editora Ática. 1977.

TOLEDO, Caio Navarro (org.). Intelectuais e política no Brasil: a experiência do ISEB. Rio de Janeiro: Revan, 2005.

WEFFORT, Francisco. 0 populismo na política brasileira. $5^{\underline{a}}$ ed. Rio de Janeiro: Paz e Terra, 2003. 